\title{
Both E6 and E7 in HPV16 Promote the Glucose Uptake of GLUT1 in Lung Cancer Cells By Repressing NDRG2 Expression and Further Nuclear Translocation of $\beta$-Catenin
}

\section{Xin Wang}

The First Hospital of China Medical University: The First Affiliated Hospital of China Medical University

\section{Ming-Zhe Wu}

The First Hospital of China Medical University: The First Affiliated Hospital of China Medical University Na-Jin Gu

The First Hospital of China Medical University: The First Affiliated Hospital of China Medical University Shi-Yu Wang

White River Health System, Batesville, AR 72501

Hong-Tao Xu

The First Hospital of China Medical University: The First Affiliated Hospital of China Medical University Qing-Chang Li

The First Hospital of China Medical University: The First Affiliated Hospital of China Medical University Guang-Ping Wu ( $\square$ wug_ping@sina.com )

The First Affiliated Hospital and College of Basic Medical Sciences, China Medical University https://orcid.org/0000-0003-3478-6868

\section{Research}

Keywords: HPV, GLUT1, NDRG2, lung cancer, glucose uptake

Posted Date: June 8th, 2021

DOI: https://doi.org/10.21203/rs.3.rs-573879/v1

License: (c) (i) This work is licensed under a Creative Commons Attribution 4.0 International License. Read Full License 


\section{Abstract}

Background: HPV16 is the most common infection subtype, among which E6 and E7 proteins are the most common carcinogenic proteins. Our previous studies found that E6 and E7 proteins regulated the expression of GLUT1 through multiple molecular signaling pathways in lung cancer. However, whether they can regulate the glucose uptake of GLUT1 and the underlying molecular mechanism has not been identified.

Methods: The modulating effects of E6 or E7, NDRG2, $\beta$-catenin, and GLUT1 were detected by double directional genetic manipulations in lung cancer cell lines; The immunofluorescence was used to detect the effect of NDRG2 on the nuclear translocation of $\beta$-catenin; The glucose uptake level of GLUT1 was observed under the confocal microscope.

Results: We demonstrated for the first time that E6 and E7 had inhibitory effects of NDRG2 which further resulted in increased $\beta$-catenin expression and promoted $\beta$-catenin nuclear translocation, furthermore promoted the expression and glucose uptake of GLUT1. Therefore, we hypothesized both E6 and E7 in HPV16 promoted the expression and glucose uptake of GLUT1 through HPV-NDRG2- $\beta$-catenin-GLUT1 axis.

Conclusion: Our findings confirmed the regulatory role of tumor suppressor NDRG2 in the pathogenesis of lung cancer, and we further demonstrate the detail relationships among E6 and E7, NDRG2, $\beta$-catenin, and GLUT1; which provided a novel therapeutic target for tumor treatment.

\section{Background}

In 1980, Syrjänen first proposed the hypothesis of the role of HPV infection in the occurrence of bronchosquamous cell carcinoma ${ }^{1}$. After that, more and more investigative studies found that high-risk HPVs, especially type 16, were associated with a subset of lung cancers in individuals without a history of tobacco exposure in Asians ${ }^{2,3}$. Persistent infection with HPV is a necessary factor for lung cancer development ${ }^{4}$. Furthermore, both E6 and E7 proteins in HPV16 are the main oncogenes during the process ${ }^{5}$. Chlon et al demonstrated that $\mathrm{E} 6$ protein inhibited cell apoptosis mainly by binding and degrading p53 gene ${ }^{6}$. While Todorovic et al showed that E7 protein promoted cell proliferation mainly by inhibiting retinoblastoma protein $(\mathrm{pRb})^{7}$.

$\mathrm{N}$-myc downstream-regulated gene 2 (NDRG2), a member of the NDRG family, was expressed widely in normal tissues, but was downregulated in some types of tumor tissues ${ }^{8,9}$. Also, NDRG2 inhibited the growth, proliferation and invasion of tumor cells ${ }^{10}$. Thus, NDRG2 was considered as the tumor suppressor gene ${ }^{11,12}$. It has been reported that NDRG2 is a direct target gene of $p 53^{13-15}$. Therefore, we hypothesized that E6 protein inactivate NDRG2 by degrading p53 gene. However, the association of E7 protein and NDRG2 has not been reported. In colon cancer cells, NDRG2 inhibited glycolysis and glutaminolysis by repressing c-Myc expression ${ }^{16}$. Shi et al proved that glycolysis in clear cell renal 
carcinoma was also significantly suppressed by NDRG $2^{17}$. Taken together, these findings strongly indicated that NDRG2 played a key point in aerobic glycolysis to fuel the bioenergy for cancer.

Kim et al confirmed that NDRG2 modulated $\beta$-catenin via the regulation of GSK-3 $\beta$ phosphorylation in human colon carcinoma ${ }^{18}$. $\beta$-catenin was the central downstream effector of Wnt signaling pathway and played an important role in cancer cell proliferation and growth ${ }^{19}$. The intracellular concentration of $\beta$ catenin was regulated by interaction with GSK-3 $\beta$ and phosphorylation at its $\mathrm{N}$-terminus, which resulted in $\beta$-catenin degradation. Intracellular $\beta$-catenin accumulated and resulted in itself translocation from cytoplasm to nuclear when phosphorylated ${ }^{20-22}$. However, the NDRG2-mediated regulation of $\beta$-catenin in lung cancer remained unknown. Some studies showed that GLUT1 was a downstream gene of $\beta$ catenin ${ }^{23,24}$. Therefore, we sought to determine the role of $\beta$-catenin in NDRG2 regulating GLUT1 expression and glucose uptake in lung cancer cells.

Cancer cells rewire their metabolism by Warburg Effect to promote malignant growth, proliferation, and long-term maintenance. Compared with normal cells, cancer cells consume a great quantity of glucose through glycolysis to fulfill energetic demands even in aerobic conditions ${ }^{25-27}$. The glucose transporter GLUT1, a main carrier of glucose uptake, played a critical role in Warburg Effect ${ }^{28}$. During cancer development, the activation of oncogene and inactivation of tumor suppressor gene resulted in the alterations of multiple intracellular signaling molecules, which further had effects on tumor cell glycolytic flux ${ }^{29-31}$. Our previous research showed that E6 and E7 proteins regulated the GLUT1 expression through multiple molecular signaling pathways ${ }^{32,33}$. However, recent research showed that the ability of GLUT1 to transport glucose is not directly related to the GLUT1 expression level, and most of the overexpressed GLUT1 proteins were in a non-functional state in the cytoplasm. One way to activate GLUT1 was translocation of GLUT1 from the cytoplasm to the plasma membrane. By doing this, cancer cells transported more extracellular glucose into the cells ${ }^{34,35}$. Thus it is necessary to further detect the level of glucose absorption to determine the effects of E6 or E7, NDRG2, and $\beta$-catenin on lung cancer cell metabolism.

The aim of this study was to examine relationship among E6 or E7, NDRG2, $\beta$-catenin, GLUT1. We hypothesized that HPV16 E6/E7 promoted glucose uptake of GLUT1 through HPV-NDRG2- $\beta$-cateninGLUT1 axis. Our results demonstrated for the first time that both E6 and E7 proteins in lung cancer cells inhibited NDRG2 expression. The repression of NDRG2 promoted the overexpression and nuclear translocation of $\beta$-catenin, $\beta$-catenin further upregulated the expression of GLUT1 at both protein and mRNA levels, as well as promoted glucose uptake of GLUT1.

\section{Materials}

This study was approved by the Ethics Committee of the First Hospital of China Medical University Cell culture and plasmids 
Lung cancer cell lines $\mathrm{NCl}-\mathrm{H} 460$ and $\mathrm{A} 549$ were purchased from the cell bank of Chinese Academy of Science (Shanghai, China), cultured in HyClone (Logan, UT, USA) RPMI 1640 medium, containing 10\% fetal bovine serum at $37^{\circ} \mathrm{C}$ with $5 \% \mathrm{CO}_{2}$. The cells were cultured in 6-well plates for 24 hours before transfection or interference.

The plasmid of pEGFP-N1-HPV16 E6, pEGFP-N1-HPV16 E7, and pEGFP-N1 were kind gifts from Prof Xudong Tang (Institute of Biochemistry and Molecular Biology, Guangdong Medical College, China). Small-interfering RNA (siRNA) was performed to silence the expression of specific genes. HPV16 E6 siRNA and HPV16 E7 siRNA were purchased from RIBOBIO (Guangzhou, China). NDRG2 siRNA and $\beta-$ catenin siRNA were purchased from Proteintech (Wuhan, China). Scrambled siRNA was used as a nonspecific siRNA control.

\section{Transfection}

Cells were transiently transfected with plasmids using the Lipofectamine 3000 Transfection Kit (Invitrogen, Carlsbad, CA, USA) following the manufacture's instruction. Transfection with empty vector and mock transfection were served as the controls. The cells were harvested 48 hours after transfection to measure the protein levels by western blotting and 24 hours to measure the mRNA levels by quantitative reverse transcriptase-polymerase chain reaction (RT-qPCR).

\section{Western blotting}

The Western-blot assay was described in reference with PMID $31839825^{33}$. Mouse anti-human HPV16 E6 monoclonal antibody (1:700; Abcam, Boston, MA, USA), rabbit anti-human HPV16 E7 polyclonal antibody (1:200; Bioss Biotechnology Co., Ltd, Beijing, China), NDRG2 antibody (1:2000; Proteintech Group, Wuhan, China), $\beta$-catenin antibody (1:500; Wanleibio, China), GLUT1 antibody (1:500; Wanleibio, China), $\beta$-tubulin antibody (1:1000; Sino Biological, Beijing, China). After incubation with appropriate secondary antibodies anti-mouse or anti-rabbit IgG (Cell Signaling Technology, Beverly, MA) at $37^{\circ} \mathrm{C}$ for 2 hours, protein bands were visualized using ECL Western blot kit (advansta, USA) and detected using Bio Imaging System (UVP Inc., Upland, CA, USA). Protein bands were visualized using electrochemiluminescence substrate (Pierce) and detected by using Biolmaging Systems (DNR, Jerusalem, Israel). $\beta$-tubulin protein levels were used as the control group to calculate relative protein levels.

Quantitative reverse transcription PCR

The Quantitative reverse transcription PCR assays described in reference with PMID $31839825^{33}$. Experiments were repeated in triplicate. The primers used are shown in Table 1. The amplified products of E6, E7, NDRG2, $\beta$-catenin, GLUT1, and GAPDH were confirmed by correct sizes on an agarose DNA gel. Products were extracted and purified from the gel, and sent for DNA sequencing, respectively. The sequencing results were $100 \%$ correct. 
Table 1

Sequencesand features of primers used for qRT-PCR

\begin{tabular}{|c|c|c|c|c|}
\hline Gene & $\begin{array}{l}\text { Forward/ } \\
\text { Reverse }\end{array}$ & Sequence & Size(bp) & mRNA \\
\hline \multirow[t]{2}{*}{ E6 } & 270 & GTATGGAACAACATTAGAACAGCAA & 81 & KX545363 \\
\hline & 350 & AGTGGCTTTTGACAGTTAATACAC & & \\
\hline \multirow[t]{2}{*}{ E7 } & 482 & GCATGGAGATACACCTACATTG & 273 & KX545363 \\
\hline & 754 & TGGTTTCTGAGAACAGATGG & & \\
\hline \multirow[t]{2}{*}{ NDRG2 } & 1786 & GAGAGGAGATCGGAAAGCCG & 339 & NC_000014.9 \\
\hline & 2124 & AAGATGGTTACCGGGGCTTG & & \\
\hline \multirow{2}{*}{$\begin{array}{l}\beta- \\
\text { catenin }\end{array}$} & 26331 & CTGGTGGGCTGCAGAAAATG & 175 & NC_000003.12 \\
\hline & 26505 & GGAATGACATGACACTGGAGGT & & \\
\hline \multirow[t]{2}{*}{ GLUT1 } & 1071 & CTGGCATCAACGCTGTCTTC & 167 & NM_006516.3 \\
\hline & 1237 & GCCTATGAGGTGCAGGGTC & & \\
\hline \multirow[t]{2}{*}{ GAPDH } & 50 & TTCTTTTGCGTCGCCAGCCGAG & 71 & XM_019023188.1 \\
\hline & 120 & CCAGGCGCCCAATACGACCAAA & & \\
\hline
\end{tabular}

Immunofluorescence

The immunofluorescence assays described in reference with PMID $31839825^{33}$. $\beta$-catenin antibody (1:50; Cell Signaling Technology, Danvers, MA, USA) was used in the assay. Images were obtained on a fluorescent microscopy (BX-51, Olympus Corporation, Tokyo, Japan).

Glucose uptake assay

The level of glucose absorption was measured using the glucose analog 2-NBDG (BioVision, CA, USA) as a fluorescent probe. Cells were seeded in 24-well tissue culture plates at a density of $2-5 \times 10^{4}$ cells per well. After 10 hours, removed regular culture medium (10\% FBS). Cells were transfected with E6, E7, siE6, siE7, siNDRG2, siß-catenin or untransfected in $400 \mu \mathrm{l}$ cell culture medium with $0.5 \% \mathrm{FBS}$. After incubated cells for 3 hours, 4 ul 2-NBDG was added to each well and incubated for 30 minutes at $37^{\circ} \mathrm{C}$ with $5 \% \mathrm{CO}_{2}$. To measure the level of 2-NBDG, the stained cells were observed under the fluorescent microscopy (BX-51, Olympus Corporation, Tokyo, Japan).

\section{Statistical analysis}


Statistical analyses were completed using SPSS 22.0 software (IBM) for Windows in this study. All data shown were mean \pm standard deviation (SD) of at least three separate experiments. Independent Student t-test or one-way ANOVA were used to compare the continuous variables between the two groups or more than two groups. $P<0.05$ was considered to be statistically significant.

\section{Results}

The screening of lung cancer cell lines

Based on our previous results, $\mathrm{H} 460$ cell line was low E6 and E7 expression cell line, and A549 cell was high E6 and E7 expression cell line. ${ }^{32}$ In order to examine the expression of NDRG2 and $\beta$-catenin, we screened in four lung cancer cell lines, A549, H1299, H460 and LK2, using western blot (S1 FigA). As is illustrated, the high expression level of NDRG2 was observed in H460 but low in A549. The expression level of $\beta$-catenin was high in A549. Therefore, we selected A549 and H460 cell lines to investigate the function of NDRG2 and $\beta$-catenin on regulating GLUT1 in vitro.

Both E6 and E7 inhibited the expression of NDRG2 but promoted the expression of $\beta$-catenin and GLUT1

We first detected the expression level of E6 or E7 after transfection or siRNA interference, and then conducted the subsequent experiments. Western blot and qRT-PCR analysis revealed that the overexpression of E6 or E7 notably inhibited the NDRG2 expression at both protein and mRNA levels but promoted the $\beta$-catenin expression only at the protein level and GLUT1 expression at both protein and mRNA levels. The results were shown in Fig. 1A and B. In addition, the knockdown of E6 or E7 in A549 cell line, a complete reverse result was obtained. They were shown in Fig. $1 \mathrm{C}$ and $\mathrm{D}$.

The repression of NDRG2 led to upregulate the expression of $\beta$-catenin and GLUT1

We further examined the function of NDRG2 on the regulation of $\beta$-catenin and GLUT1 expression. Then, high NDRG2 expression cell line $\mathrm{H} 460$ was selected. NDRG2 repression in $\mathrm{H} 460$ cell line was achieved by the NDRG2-specific siRNA. NDRG2-nonspecific siRNA and mock specific siRNA were used to serve as the controls. As shown in Fig. 2A, the repression of NDRG2 led to upregulate the $\beta$-catenin expression only at the protein level and GLUT1 expression at both protein and mRNA levels. There was little or no change in NDRG2 mock siRNA and nonspecific siRNA.

Knocked NDRG2 promoted $\beta$-catenin nuclear translocation

In order to further confirm the regulatory effect of NDRG2 on $\beta$-catenin, we used NDRG2-specific siRNA to inhibit the expression of NDRG2 in $\mathrm{H} 460$ cell line. Then the test was performed by immunofluorescence techniques. As shown in Fig. 2B, the knocked of NDRG2 significantly promoted $\beta$-catenin nuclear translocation..

The knockdown of $\beta$-catenin inhibited the expression of GLUT1 
To determine the consequence of inhibiting $\beta$-catenin, we used $\beta$-catenin-specific siRNA to knock down the expression of $\beta$-catenin in A549 cell line. Besides, $\beta$-catenin-nonspecific siRNA and mock specific siRNA were used to serve as the controls. As shown in Fig. 2C, GLUT1 was markedly decreased at both protein and mRNA levels after knocked $\beta$-catenin. In addition, $\beta$-catenin-nonspecific siRNA and mock specific siRNA showed minimal or no change.

The overexpression of E6/E7 and the knockdown of NDRG2 significantly promoted the glucose uptake of GLUT1, whereas the knockdown of E6/E7 and $\beta$-catenin obviously inhibited the glucose uptake of GLUT1

To investigate the functional roles of E6, E7, NDRG2 and $\beta$-catenin on the glucose uptake of GLUT1, we transfected E6 or E7 vectors and siNDRG2 in H460 cell line, and knocked down E6, E7 and $\beta$-catenin in A549 cell line. Our results showed that overexpression of both E6 and E7, as well as knockdown of NDRG2 significantly promoted the glucose uptake of GLUT1 in H460. On the contrary, knockdown of E6, E7 and $\beta$-catenin inhibited the glucose uptake of GLUT1 in A549. More specifically, the levels of glucose uptake were significantly higher than those of the control group by fluorescence microscopy in lung cancer cells. Results were presented in Figure.3A-D.

\section{Discussion}

Our previous work found that the overexpression of HPV16 E6/E7 upregulated the expression of GLUT1 at protein and mRNA levels in lung cancer cells ${ }^{32,33}$. However, the underline molecular mechanisms were still need investigation. It was reported that the tumor suppressor NDRG2 inhibited tumor glycolysis in some cancer cells by suppressing GLUT $1^{16,17}$. In our current study, first we demonstrated the overexpression of E6 or E7 protein inhibited NDRG2 expression at both protein and mRNA levels in lung cancer cells. Further E6 or E7 and NDRG2 regulatory mechanism studies were conducted.

The Wnt signaling pathway had been shown to participate in the reprogramming of cancer cell metabolism ${ }^{36}$, and the activation of which enhances the glucose metabolism through glycolysis ${ }^{37}$. While $\beta$-catenin was the central downstream effector of Wnt signaling pathway ${ }^{19}$. It was reported that NDRG2 modulates $\beta$-catenin signaling in human colon carcinoma ${ }^{18}$. A recent study confirmed that NDRG2 inhibited the proliferation of colorectal cancer cells by suppressing the expression of $\beta$-catenin ${ }^{16}$. Another investigative group further demonstrated that NDRG2 inhibited the proliferation of breast cancer cells via regulating $\beta$-catenin expression and nuclear translocation ${ }^{22}$. Based on these findings, we hypothesized that NDRG2 regulated the expression and glucose uptake of GLUT1 through $\beta$-catenin. Knockdown endogenous NDRG2 in $\mathrm{H} 460$ cell line, we found that it only enhanced the expression of $\beta$-catenin at the protein level, but almost no change at the mRNA level. The GLUT1 expression was significantly increased both at the protein and mRNA levels. Meanwhile, the glucose uptake of GLUT1 obviously increased as well. We also demonstrated that the loss of NDRG2 promoted $\beta$-catenin nuclear translocation by Immunofluorescence staining. 
Glucose uptake, a critical metabolic control point in Warburg effect, is mainly mediated by the integral membrane transporter GLUT1. Cell surface expression of GLUT1 is increased in diverse cancers. It is the activated GLUT1 on the plasma membrane to transport a large quantity of extracellular glucose into the cell for glycolysis. Remarkably, the activated GLUT1 is not directly relevant to the expression level of GLUT1 in cytoplasm. The majority of the overexpressed GLUT1 proteins in the cytoplasm are in a nonfunctional state, because they are unable to transport the extracellular glucose. The translocation of intracellular GLUT1 to the plasma membrane determines the GLUT1 activation ${ }^{34,35}$. Thus, we conducted glucose uptake assay. In our present study, we validated that E6, E7 and $\beta$-catenin had enhanced effects on the glucose uptake of GLUT1, and on the hand, NDRG2 inhibited the glucose absorption of lung cancer cells.

\section{Conclusions}

Our study demonstrated for the first time that both E6 and E7 proteins had inhibitory effects on NDRG2, which resulted in increased $\beta$-catenin expression and nuclear translocation, and increased $\beta$-catenin further promoted GLUT1 expression and its glucose uptake. Therefore, E6 and E7 regulated GLUT1 through HPV-NDRG2- $\beta$-catenin-GLUT1 axis. Our findings demonstrated the regulatory role of tumor suppressor NDRG2 in the pathogenesis of lung cancer, and provided a novel therapeutic target for tumor treatment.

\section{Abbreviations}

HPV: Human papillomavirus; pRb: retinoblastoma protein; NDRG2: N-myc downstream-regulated gene 2; GLUT1: Glucose transporter 1

\section{Declarations}

\section{Ethics approval and consent to participate}

Ethical approval was obtained for the experimental procedures by the Ethics Committee of the First Hospital of China Medical University (APPROVAL NUMBER/2016-125), Shenyang, China.

\section{Consent for publication}

All authors have agreed to publish this manuscript.

\section{Availability of data and materials}

All data generated or analyzed during this study are included in this published article.

\section{Competing interests}

The authors declare that they have no competing interests.

\section{Funding}


The author(s) disclosed receipt of the following financial support for the research, authorship, and/or publication of this article: The present study was supported by grants from the National Natural Science Foundation of China (Grant No.81171650 and 81672082)

Author contributions: Xin Wang, Hong-Tao Xu, Qing-Chang Li, and Guang-Ping Wu contributed to designed and supervised the study. Xin Wang, Ming-Zhe Wu, and Na-Jin Gu jointly participated in statistical data analysis and interpretation. Shiyu Wang helped in language editing in this article. All authors critically reviewed of the manuscript and approved the final versin for submission.

\section{Acknowledgements}

Not applicable.

\section{Statement of Human and Animal Rights}

This article does not contain any studies with human and animal subjects.

\section{Statement of Informed Consent}

There are no human subjects in this article and informed consent is not applicable.

\section{ORCID iD}

Guang-Ping Wu https://orcid.org/0000-0003-3478-6868

\section{References}

1. Syrjänen KJ. Epithelial lesions suggestive of a condylomatous origin found closely associated with invasive bronchial squamous cell carcinomas. Respiration. 1980;40(3):150-60.

2. Zhai K, Ding J, Shi HZ. HPV and lung cancer risk: a meta-analysis. J Clin Virol. 2015;63:84-90.

3. Yu Y, Liu X, Yang Y, et al. Effect of FHIT loss and p53 mutation on HPV-infected lung carcinoma development. Oncol Lett. 2015;10(1):392-8.

4. Colombara DV, Manhart LE, Carter JJ, Hawes SE, Weiss NS, Hughes JP, Barnett MJ, Goodman GE, Smith JS, Qiao YL, Galloway DA. Prior human polyomavirus and papillomavirus infection and incident lung cancer: a nested case-control study. Cancer Causes Control. 2015;26(12):1835-44.

5. Zhang E, Feng X, Liu F, Zhang P, Liang J, Tang X. Roles of PI3K/Akt and c-Jun signaling pathways in human papillomavirus type 16 oncoprotein-induced HIF-1a, VEGF, and IL-8 expression and in vitro angiogenesis in non-small cell lung cancer cells. PLoS One. 2014;9(7):e103440.

6. Chlon TM, Hoskins EE, Mayhew CN, Wikenheiser-Brokamp KA, Davies SM, Mehta P, Myers KC, Wells $\mathrm{JM}$, Wells SI. High-risk human papillomavirus E6 protein promotes reprogramming of Fanconi anemia patient cells through repression of p53 but does not allow for sustained growth of induced pluripotent stem cells. J Virol. 2014;88:11315-26. 
7. Todorovic B, Hung K, Massimi P, Avvakumov N, Dick FA, Shaw GS, Banks L, Mymryk JS. Conserved region 3 of human papillomavirus $16 \mathrm{E} 7$ contributes to deregulation of the retinoblastoma tumor suppressor. J Virol. 2012;86:13313-23.

8. Hu XL, Liu XP, Deng YC, Lin SX, Wu L, Zhang J, Wang LF, Wang XB, Li X, Shen L, Zhang YQ, Yao LB. Expression analysis of the NDRG2 gene in mouse embryonic and adult tissues. Cell tissue research. 2006;325:67-76.

9. Liu N, Wang L, Liu X, Yang Q, Zhang J, Zhang W, Wu Y, Shen L, Zhang Y, Yang A, Han H, Zhang J, Yao L. Promoter, methylation, mutation, and genomic deletion are involved in the decreased NDRG2 expression levels in several cancer cell lines. Biochem Biophys Res Commun. 2007;358:164-9.

10. Deng Y, Yao L, Chau L, Ng SS, Peng Y, Liu X, Au WS, Wang J, Li F, Ji S, Han H, Nie X, Li Q, Kung HF, Leung SY, Lin MC. N-Myc downstream-regulated gene 2 (NDRG2) inhibits glioblastoma cell proliferation. International journal of cancer Journal international du cancer. 2003;106:342-7.

11. Furuta H, Kondo Y, Nakahata S, Hamasaki M, Sakoda S, Morishita K. NDRG2 is a candidate tumorsuppressor for oral squamous-cell carcinoma. Biochem Biophys Res Commun. 2010;391:1785-91.

12. Hwang J, Kim Y, Kang HB, Jaroszewski L, Deacon AM, Lee H, Choi WC, Kim KJ, Kim CH, Kang BS, Lee JO, Oh TK, Kim JW, Wilson IA, Kim MH. Crystal structure of the human N-Myc downstream-regulated gene 2 protein provides insight into its role as a tumor suppressor. J Biol Chem. 2011;286:12450-60.

13. Liu N, Wang L, Li X, Yang Q, Liu X, Zhang J, Zhang J, Wu Y, Ji S, Zhang Y, Yang A, Han H, Yao L. NMyc downstream-regulated gene 2 is involved in p53-mediated apoptosis. Nucleic Acids Res. 2008;36(16):5335-49.

14. Li Y, Xu N, Cai L, Gao Z, Shen L, Zhang Q, Hou W, Zhong H, Wang Q, Xiong L. NDRG2 is a novel p53associated regulator of apoptosis in C6-originated astrocytes exposed to oxygen-glucose deprivation. PLoS One. 2013;8(2):e57130.

15. Cao W, Zhang JL, Feng DY, Liu XW, Li Y, Wang LF, Yao LB, Zhang H, Zhang J. The effect of adenovirus-conjugated NDRG2 on p53-mediated apoptosis of hepatocarcinoma cells through attenuation of nucleotide excision repair capacity. Biomaterials. 2014;35(3):993-1003.

16. Xu X, Li J, Sun X, Guo Y, Chu D, Wei L, Li X, Yang G, Liu X, Yao L, Zhang J, Shen L. Tumor suppressor NDRG2 inhibits glycolysis and glutaminolysis in colorectal cancer cells by repressing c-Myc expression. Oncotarget. 2015;6(28):26161-76.

17. Shi W, Xu X, Yan F, Wang B, Zhao H, Chan A, Ren Z, Ma Y, Wang F, Yuan J. N-Myc downstreamregulated gene 2 restrains glycolysis and glutaminolysis in clear cell renal cell carcinoma. Oncol Lett. 2017;14(6):6881-7.

18. Kim YJ, Yoon SY, Kim JT, Song EY, Lee HG, Son HJ, Kim SY, Cho D, Choi I, Kim JH, Kim JW. NDRG2 expression decreases with tumor stages and regulates TCF/ $\beta$-catenin signaling in human colon carcinoma. Carcinogenesis. 2009;30(4):598-605.

19. Clevers H. Wnt/beta-catenin signaling in development and disease. Cell. 2006;127:469-80.

20. Zheng YW, Li ZH, Lei L, Liu CC, Wang Z, Fei LR, Yang MQ, Huang WJ, Xu HT. FAM83A Promotes Lung Cancer Progression by Regulating the Wnt and Hippo Signaling Pathways and Indicates Poor 
Prognosis. Front Oncol. 2020;10:180.

21. Lee SY, Jeon HM, Ju MK, Kim CH, Yoon G, Han SI, Kang HS. Wnt/Snail signaling regulates cytochrome $\mathrm{C}$ oxidase and glucose metabolism. Can Res. 2012;72(14):3607-17.

22. Zhou XL, Zhu CY, Zhang SG, Zhou ZY, Li HC, Zou W. NDRG2 inhibited the proliferation of breast cancer cells via regulating $\beta$-catenin expression and nuclear translocation. China Oncology. 2016;12:981-8.

23. Kraus D, Reckenbeil J, Wenghoefer M, Stark H, Frentzen M, Allam JP, Novak N, Frede S, Götz W, Probstmeier R, Meyer R, Winter J. Ghrelin promotes oral tumor cell proliferation by modifying GLUT1 expression. Cell Mol Life Sci. 2016;73(6):1287-99.

24. Fang Y, Shen ZY, Zhan YZ, Feng XC, Chen KL, Li YS, Deng HJ, Pan SM, Wu DH, Ding Y. CD36 inhibits $\beta$-catenin/c-myc-mediated glycolysis through ubiquitination of GPC4 to repress colorectal tumorigenesis. Nat Commun. 2019;10(1):3981.

25. Deblois G, Giguere V. Oestrogen-related receptors in breast cancer: control of cellular metabolism and beyond. Nature reviews Cancer. 2013;13:27-36.

26. Dang CV. Links between metabolism and cancer. Genes Dev. 2012;26:877-90.

27. Vaupel $P$, Schmidberger $H$, Mayer A. The Warburg effect: essential part of metabolic reprogramming and central contributor to cancer progression. Int J Radiat Biol. 2019;95(7):912-9.

28. Meng Y, Xu X, Luan H, Li L, Dai W, Li Z, Bian J. The progress and development of GLUT1 inhibitors targeting cancer energy metabolism. Future Med Chem. 2019;11(17):2333-52.

29. Hsu PP, Sabatini DM. Cancer cell metabolism: Warburg and beyond. Cell. 2008;134:703-7.

30. DeBerardinis RJ, Lum JJ, Hatzivassiliou G, Thompson CB. The biology of cancer: metabolic reprogramming fuels cell growth and proliferation. Cell Metabol. 2008;7:11-20.

31. Jones RG, Thompson CB. Tumor suppressors and cell metabolism: a recipe for cancer growth. Genes develop-ment. 2009;23:537-48.

32. Fan R, Hou WJ, Zhao YJ, Liu SL, Qiu XS, Wang EH, Wu GP. Overexpression of HPV16 E6/E7 mediated HIF-1 a upregulation of GLUT1 expression in lung cancer cells. Tumour Biol. 2016;37:4655-63.

33. Gu NJ, Wu MZ, He L, Wang XB, Wang S, Qiu XS, Wang EH, Wu GP. HPV 16 E6/E7 up-regulate the expression of both HIF-1 $a$ and GLUT1 by inhibition of RRAD and activation of NF-KB in lung cancer cells. J Cancer. 2019;10(27):6903-9.

34. Calado SM, Alves LS, Simão S, Silva GA. GLUT1 activity contributes to the impairment of PEDF secretion by the RPE. Molecular vision. 2016;22:761-70.

35. Roy S, Leidal AM, Ye J, Ronen SM, Debnath J. Autophagy-Dependent Shuttling of TBC1D5 Controls Plasma Membrane Translocation of GLUT1 and Glucose Uptake. Molecular cell. 2017;67(1):84-95.

36. Sherwood V. WNT signaling: an emerging mediator of cancer cell metabolism? Mol Cell Biol. 2015;35(1):2-10.

37. Cisternas P, Salazar P, Silva-Álvarez C, Barros LF, Inestrosa NC. Activation of Wnt signaling in cortical neurons enhances glucose utilization through glycolysis. J Biol Chem. 2016;291(50):25950-64. 
Figures

A

H460 Mock Vector E6

E6

NDRG2

$\beta$-catenin

GLUT1

$\beta$-tubulin
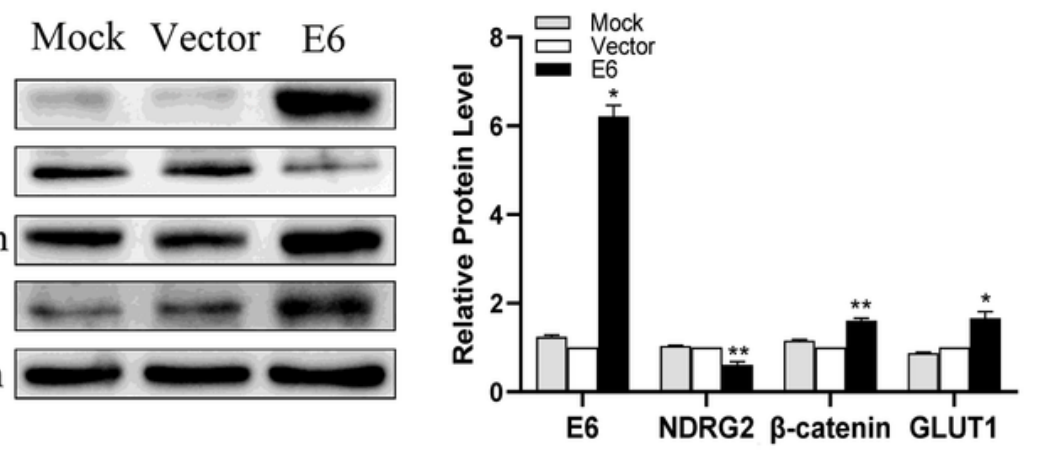

B

H460 Mock Vector E7

E7

NDRG2

$\beta$-catenin

GLUT1

$\beta$-tubulin
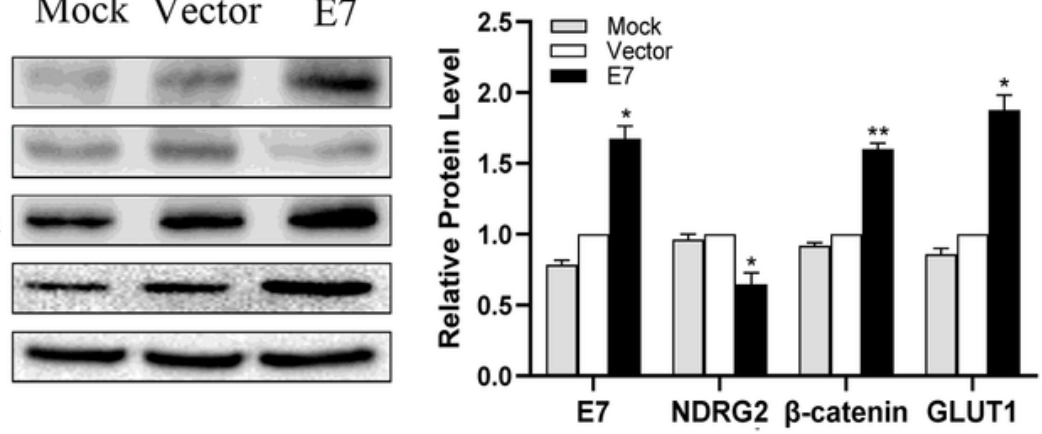

C
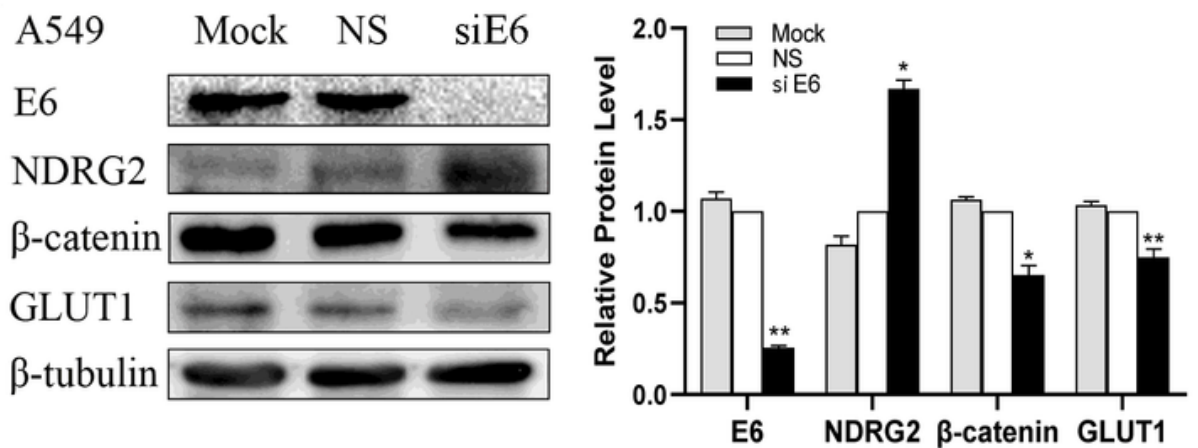

D

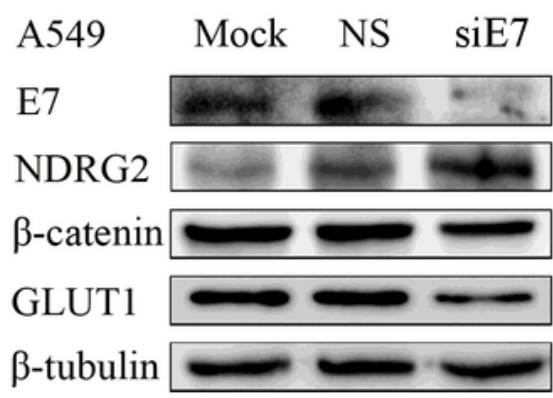

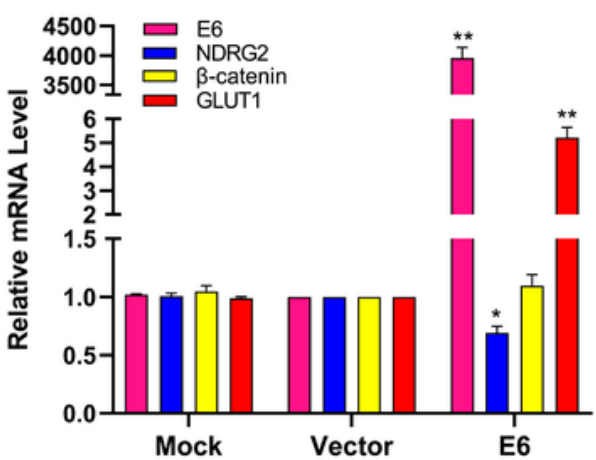

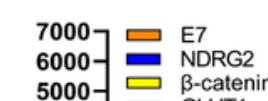

$5000-\square \beta$-cateni
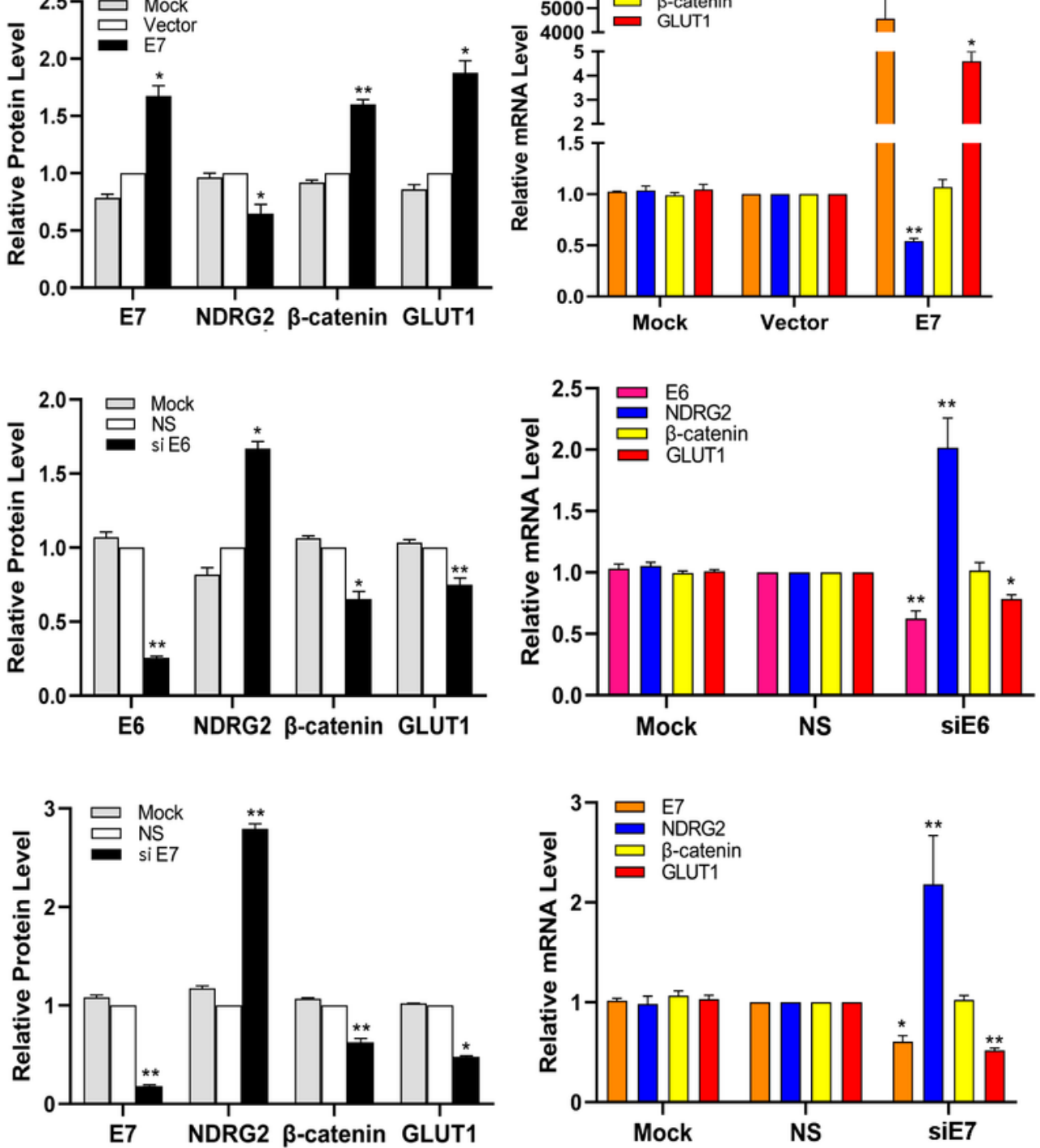

Figure 1

The effects of E6 or E7 on regulation the expression levels of NDRG2, $\beta$-catenin, and GLUT1 by transfection (A) or (B) in H460 cells. The effects of E6 or E7 on regulation the expression levels of NDRG2, 
$\beta$-catenin, and GLUT1 by siRNA transfection (C) or (D) in A549 cells. Mock: mock transfection or mock siRNA; vector: empty vector; NS: nonspecific siRNA $\left({ }^{*} p<0.05 ;{ }^{* *} p<0.0\right.$ l).

A
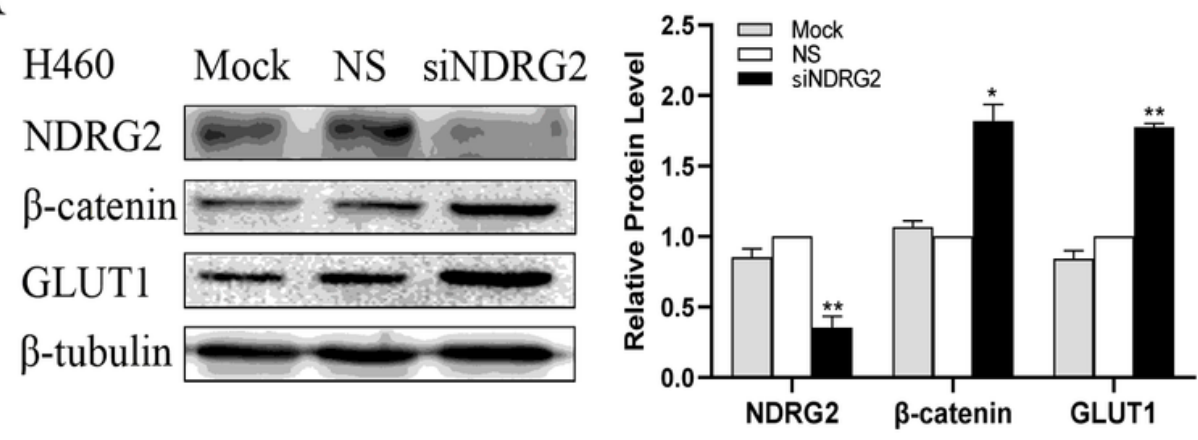

B

$\beta$-catenin

DAPI

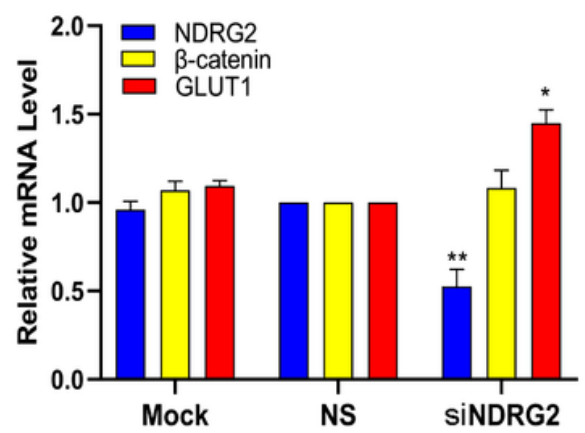

Merged

NS
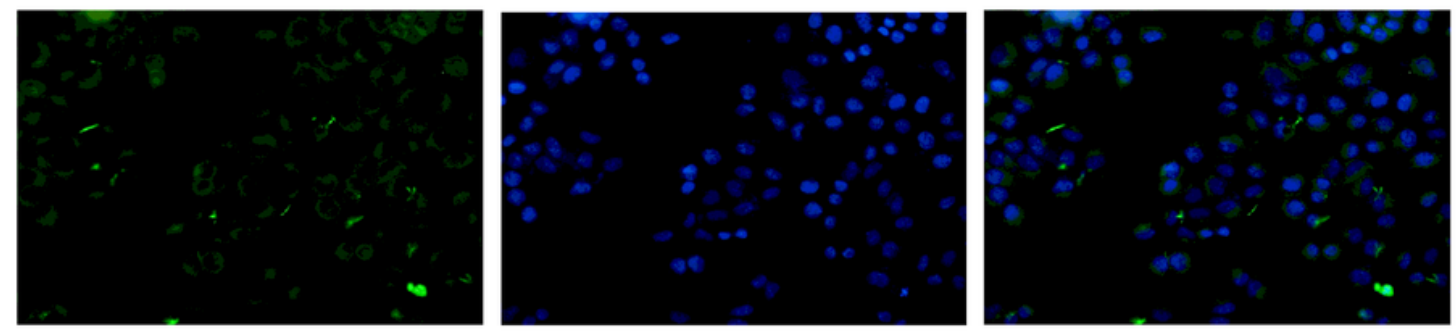

siNDRG2
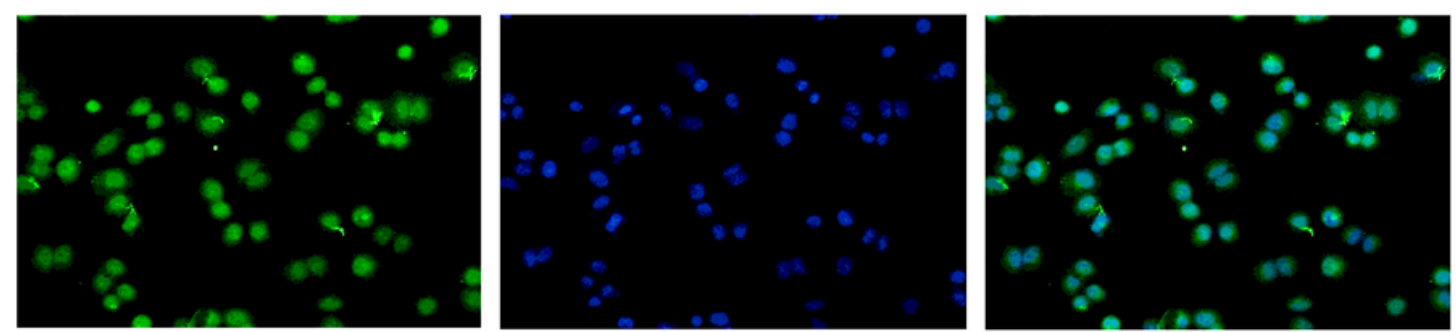

C
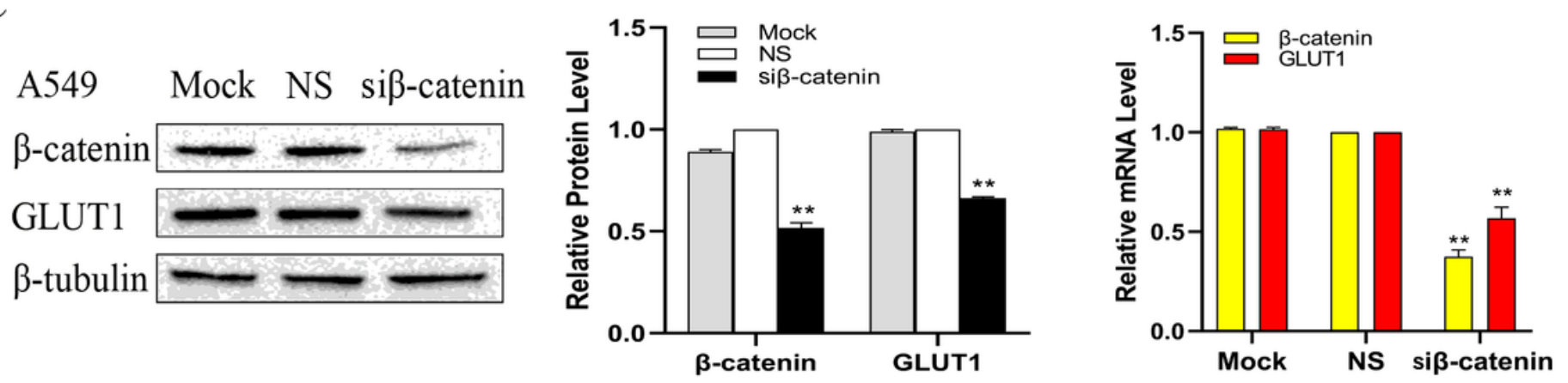

Figure 2

(A) The effects of repressing NDRG2 on the expression levels of $\beta$-catenin and GLUT1 by siRNA transfection in $\mathrm{H} 460$ cells. (B) Immunofluorescence revealed that repressing NDRG2 promoted the nuclear translocation of $\beta$-catenin obviously by siRNA transfection in H460 cells. Scale bar, 50 4 m. (C) Knocked $\beta$-catenin downregulated the GLUT1 expression obviously by siRNA transfection in A549 cells. Mock: mock siRNA; NS: nonspecific siRNA (*p<0.05; $\left.{ }^{* *} p<0.01\right)$. 

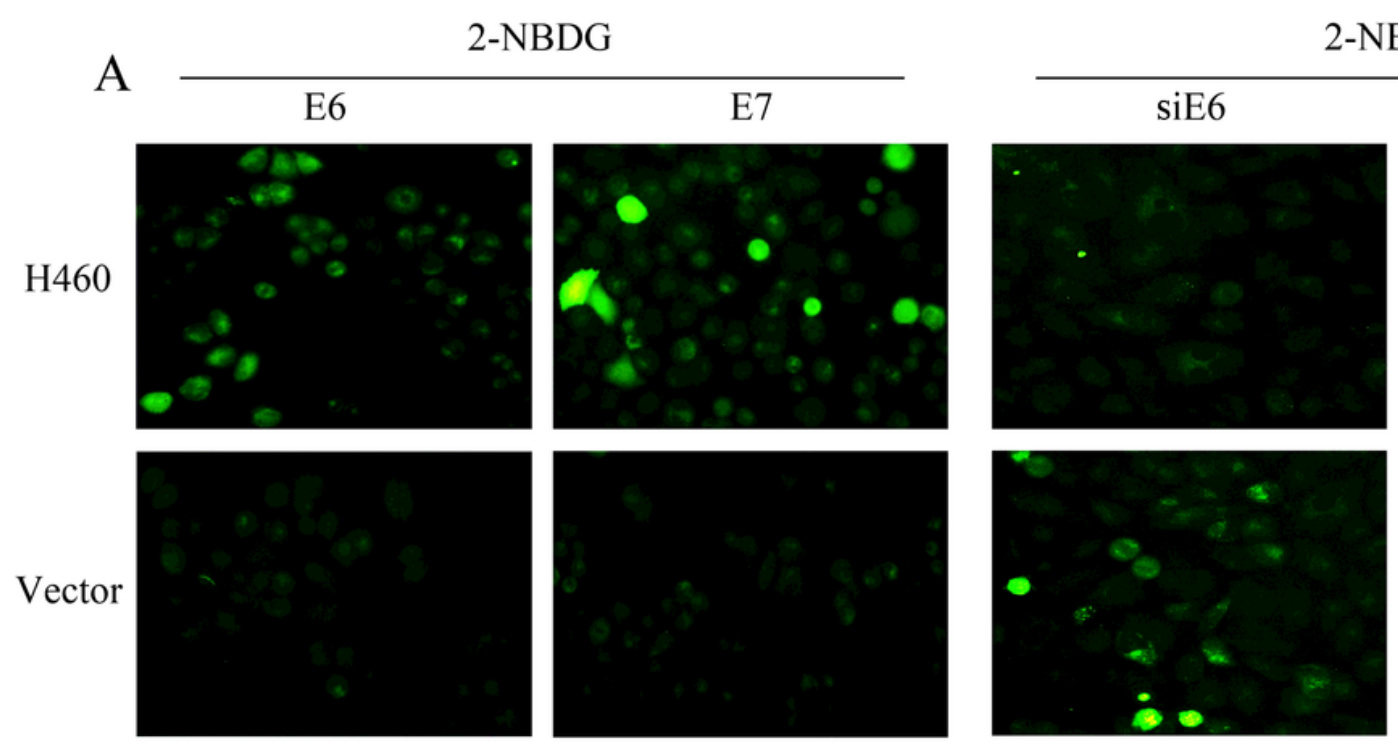

-NBDG
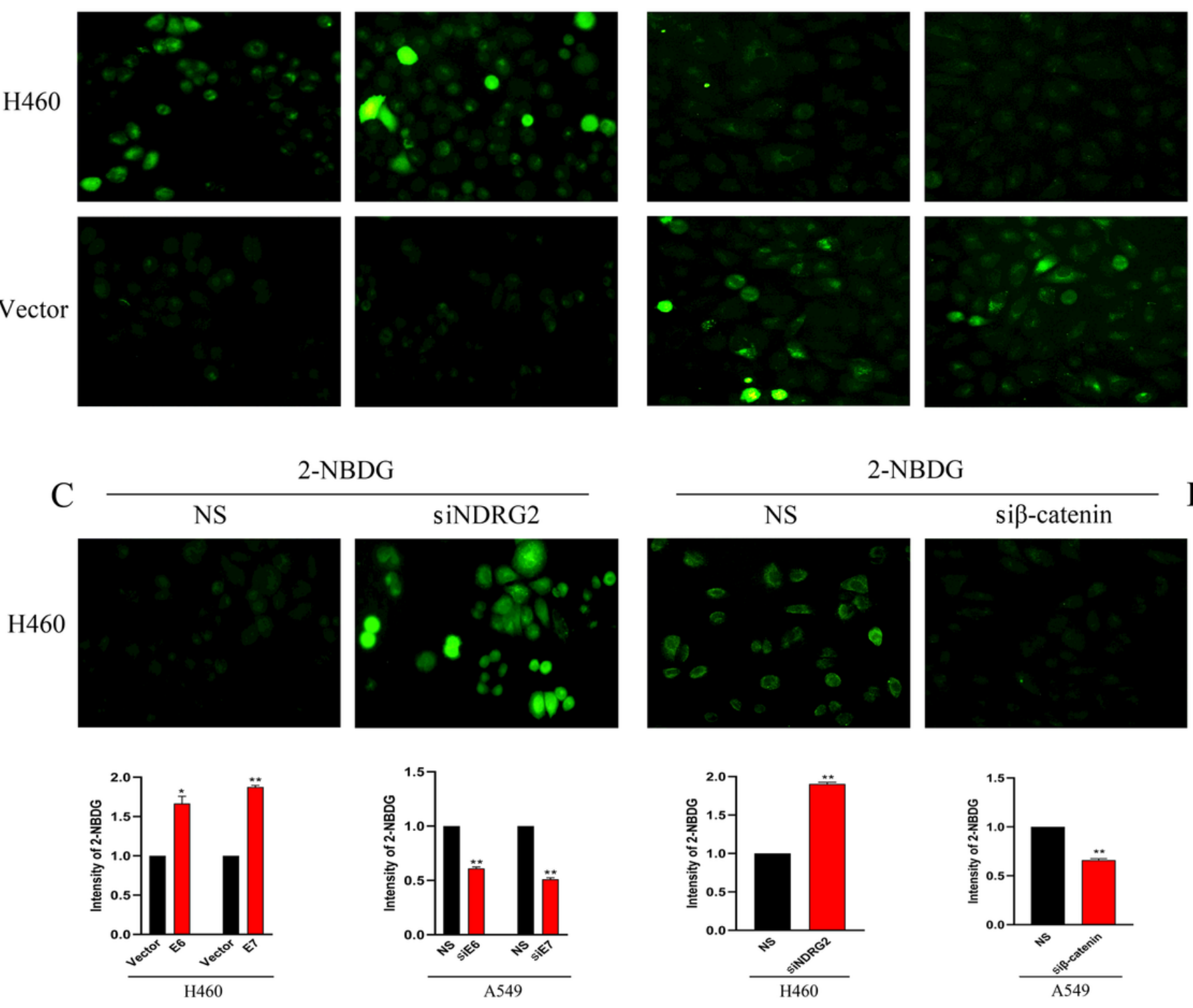

\section{Figure 3}

The effects of E6, E7, NDRG2 and $\beta$-catenin on the amount of glucose uptake by GLUT1. Glucose uptake assay was conducted to measure the cellular uptake of glucose. The changes of glucose uptake by GLUT1 after transfection with E6 or E7 were presented by (A), interference with E6 or E7 by (B), interference with NDRG2 by (C), and interference with $\beta$-catenin by (D), respectively. The relative levels of 2-NBDG were measured by fluorescence microscopy and ImageJ software respectively. $\left({ }^{*} p<0.05\right.$ versus NS group; ${ }^{* *} \mathrm{p}<0.01$ versus NS group)

\section{Supplementary Files}

This is a list of supplementary files associated with this preprint. Click to download. 
- FigS1.jpg

Page 15/15 